While British Columbia initiated the 2-dose Gardasil trial, all of the provinces and territories are interested in its outcome, says Dobson. The results will not necessarily influence the start of those other provincial or territorial programs, though, he adds.

Still, Dodson says, "it is a great example of collaboration at many levels - geographical, governmental, public health, pediatric, gynecological, oncology, virology and immunology - to answer a question of importance to public health."

The study, involving 825 girls, will begin this fall in Vancouver, Quebec City and Halifax. Each site is recruiting 275 participants in the $9-13$ and $16-26$ age range, says Carol Lajeunesse, clinical trial unit manager for the Vaccine Evaluation Centre in Vancouver.

Meanwhile, 3 provinces have announced vaccine programs.

Grade 7 Nova Scotian girls will be vaccinated over a 6 -month period during the $2007 / 08$ school year, at a cost of $\$ 2.8$ million per year.

Prince Edward Island announced in March that it would vaccinate girls in grade 6 at a cost of $\$ 400$ ooo. However, the government has changed since that time and no further information has been released.

And on Aug. 2, the Ontario government announced it will offer the vaccine to all 84000 grade 8 girls, at a cost of $\$ 117$ million over 3 years. The school-based vaccination will be administered by public health nurses.

Internationally, Australia and Italy are among countries financing the HPV vaccine. Italy is offering it free for all I2-year-old girls, while Australia is publicly funding vaccinations for both men and women.

In the United Kingdom, the Joint Committee on Vaccination and Immunisation has recommended that 12 - and I3-year-old girls receive the vaccine, and the Department of Health has agreed "in principle" with an immunization program beginning in 2008. Switzerland, Austria, Belgium, France, Germany, Luxembourg and Norway have also recommended that teenage girls receive the vaccine. - Laura Eggertson, Ottawa

DOI:I0.1503/cmaj.071048

\section{Pass me that scalpel,}

\section{instrumentalist}

$\mathrm{W}$

ait times and waiting lists are becoming so lengthy that the health care system must look to new staffing and procedural solutions so it can efficiently move more patients through operating rooms, says Dr. Gaétan Barrette, president of the Federation of Medical Specialists of Quebec.

But Barrette's proposals for reform - including the creation of a new position in the operating room, called "instrumentalist" (for handing tools to surgeons), and asking anesthesiologists to consider going back to working 2 minor operations simultaneously are drawing decidedly mixed reviews from health care professionals.

Barrette says that instrumentalists would free up at least I nurse from the duty of passing instruments to a surgeon and thus help redress the severe shortage of nurses in the province, which the Quebec Ministry of Health estimates now stands at around I500. "We believe nurses are overqualified to do that part of the job in the [operating room]," Barrette says. "Sometimes we have to cancel surgeries because we don't have enough nurses passing instruments - that's ridiculous! We will not have a shortage of instrumentalists."

Barrette says that instrumentalists could be easily recruited, because they wouldn't require any specific health care education and could be trained within a hospital. "It doesn't take a $\mathrm{PhD}$ or any medical training. If you can place a tray in a sterilizer, you can pass instruments to the surgeon. Nurses should be at the side of the patients who need them."

However, both the Canadian Nurses Association and l'Ordre des infirmières et infirmiers du Québec are concerned about accountability, particularly given that such instrumentalists wouldn't be subject to any professional laws or regulations. Marlene Smadu, president of the Canadian Nurses Association, argues that it's vital to have a registered nurse in the circulating nurse role. "That is really the role that has the oversight in terms of holistic patient care in the operating room."

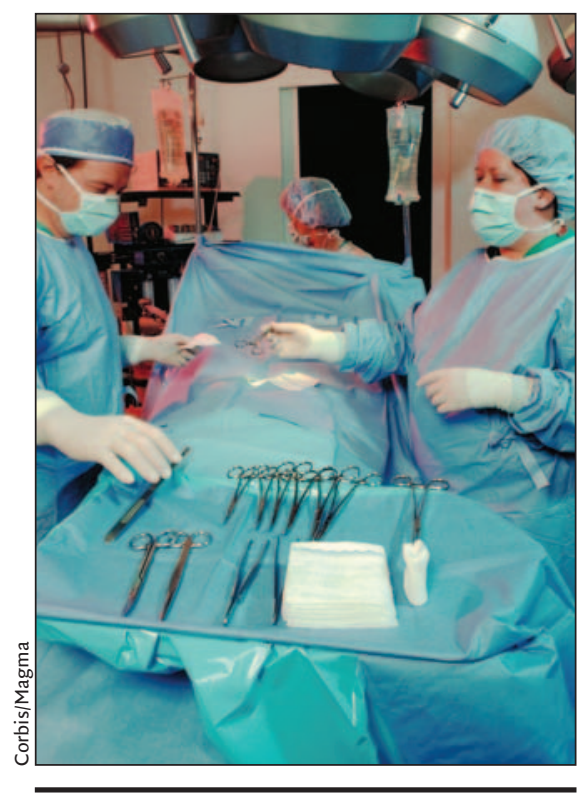

An "instrumentalist" would pass instruments to surgeons, thus freeing up nurses to perform other duties.

In a crisis, Smadu adds, scrub nurses and circulating nurses are interchangeable. "That wouldn't be the case if you've got a different kind of practitioner doing the instrumentalist role. Everyone needs to know how that person fits in."

And although Smadu believes there may be some more routine work that wouldn't require registered nurse training, she wonders about the future for instrumentalists. "I'm always concerned that we are creating these little pieces of work that are dead-end jobs for the people in them. If a person can only be an instrumentalist in I institution in Quebec, is that the kind of approach we want for a health team for the future?"

Perhaps more controversial is Barrette's suggestion that anesthesiologists simultaneously work 2 operations. "This is a much more delicate issue," Barrette stresses. "It would be absolutely unthinkable and unreasonable to go back 20 years." At that time, working 2 rooms was fairly common, but Canadian Anesthesiologists' Society guidelines now advise a I-to-I ratio with patients.

"The question is, would it be possible to determine specific situations where it would be safe and reasonable to supervise 2 minor surgeries at the same time?"

Canadian Anesthesiologists' Society President Shane Sheppard says any- 
thing is possible, "but how safe is it? We have national standards for a I-to-I ratio. That's the way it is, and that's the way it will stay." Sheppard says anesthesia care teams in Ontario, which include anesthesiology assistants and nurses, are now working with anesthesiologists to administer anesthetic for routine cases, such as cataract surgery. Training more anesthesiologist assistants could help speed up the efficiency of larger surgeries. But in the end, he says, nurse shortages need to be addressed.

Barrette has also proposed that surgical waits could be partially alleviated through new pay incentives for intensive care unit nurses.

Such measures would go a long way to reduce wait times and waiting lists, he says. "At the end of the day, you might increase throughput by more than $10 \%$ to $20 \%$. Reasonably, we can design a template that can be workable to everyone." - Elizabeth Shilts, Ottawa

DOI:I0.1503/cmaj.070964

\section{Nova Scotia paramedics}

\section{to be wired}

$\mathrm{M}$ ore accurate diagnoses are among the forecast benefits of Canada's first provincewide electronic reporting system for paramedics.

Siren ePCR will be fully implemented in Nova Scotia, at a cost of $\$ 2.2$ million over 3 years, by early next year. It's expected that more than 800 emergency services personnel will abandon their clipboards, pens and papers in favour of the computerized system that organizes patient information in a useful fomat for staff in emergency departments.

Patient information is more legible and "formatted in a way the emergency doctor can understand," says Dr. Andrew Travers, staff physician at the Queen Elizabeth II Health Sciences Centre in Halifax. "We're relying more and more on the information paramedics provide," Travers adds. "This [system] is helping us to make an accurate diagnosis."

Paramedics, meanwhile, praise the versatility, ease and speed of the system, which was developed by Medusa Medical Technologies Inc. of Halifax. "The software is designed to follow the workflow of a health care worker as they do an assessment in real time," says John Bessonette, an advanced care paramedic in Halifax. "But you don't have to start at the top of the checklist. You can start at any point in the process."

Savings in recording time along with the sophistication of the system combine to provide more detailed information for physicians, says Travers, who also serves as medical director of research with Emergency Health Services. "Instead of I page [of information], there could be 6 or $7 . "$

It includes drug and dosage information, Travers notes. "Almost by default this allows you to investigate drug interaction - [and] that's just the tip of the iceberg."

The system also automatically records a patient's address for the paramedic team and even provides a map to speed response time.

Quality assurance is also improved, says Deborah MacKay, director of communications and dispatch services with Emergency Health Services. "You can query by incident or paramedic."

MacKay says the new system also has significant, long-term clinical and research implications. Province-wide data can be collected and aggregated for use in investigating a particular issue, such as heart attack symptoms in women, or a specific process, such as intubation.

All paramedics in the province will be trained by January 2008. By then, proponents hope to iron out kinks in the system that emerged during the pilot phase. These include lost connections and an inability to print out reports in emergency departments.

The Siren ePCR system, which is now being implemented in $60 \%$ of ambulances in the United Kingdom, may also prove to be incompatible with other software in Nova Scotia's health care facilities.

"The current platform may not flow into the hospital system," says Travers. "[But] we'll deal with that when the time comes." - Donalee Moulton, Halifax

DOI:Io.I503/cmaj.070963

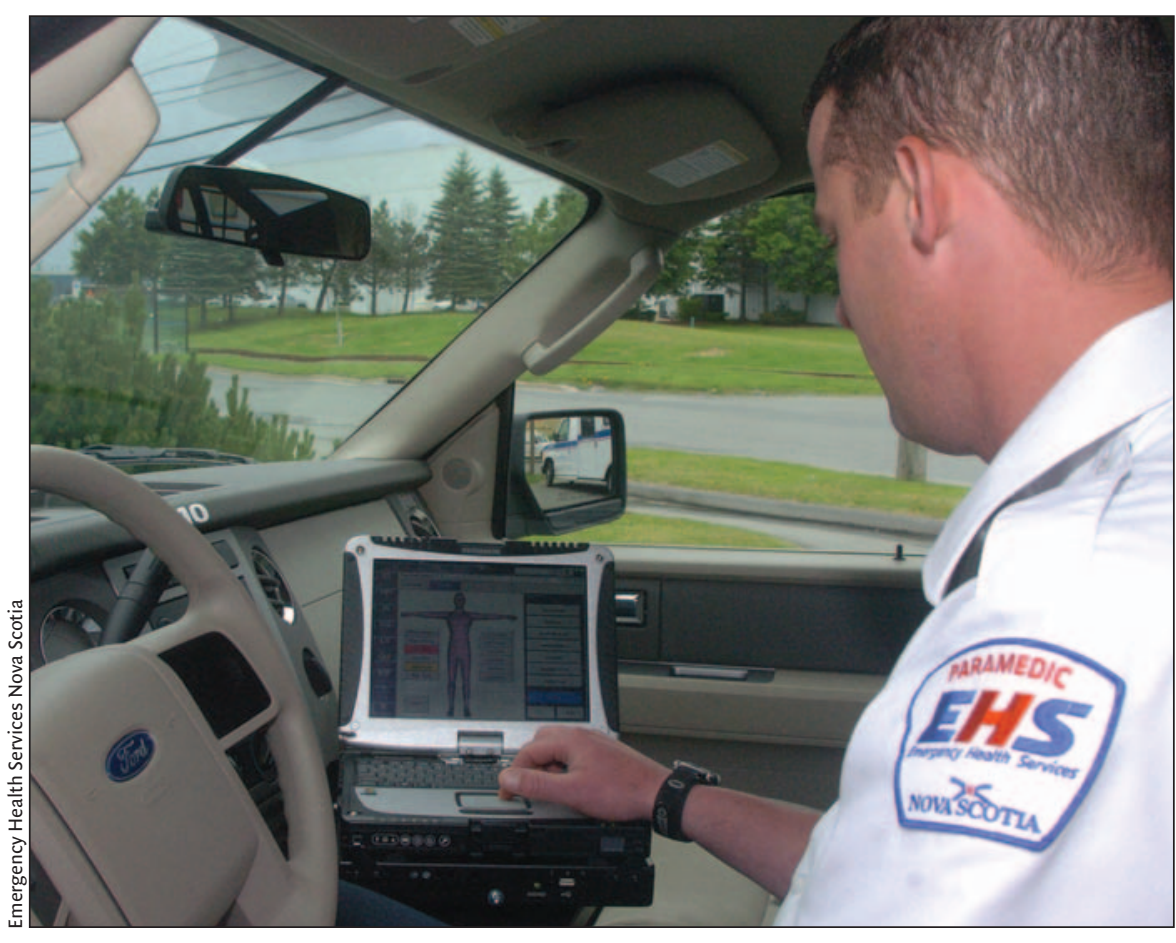

Paramedic supervisor Kevin Carey demonstrates the ease with which patient information can be entered into a new electronic reporting system being introduced in Nova Scotia. 